\title{
Effect of sulphasalazine on the radiological progression of rheumatoid arthritis
}

\author{
T PULLAR, ${ }^{1}$ J A HUNTER, ${ }^{2}$ AND H A CAPELL 3 \\ From the ${ }^{1}$ Department of Clinical Pharmacology, University of Leeds; ${ }^{2}$ Gartnavel General Hospital, \\ Glasgow; and the ${ }^{3}$ Centre for Rheumatic Diseases, Glasgow Royal Infirmary, Glasgow
}

SUMMARY We have investigated the influence of sulphasalazine, a second line antirheumatic drug, on the radiological progression of erosions in rheumatoid arthritis over a two year period its 41 patients. Hand radiograph scores deteriorated significantly over this period, but in a group ơf 31 patients in whom one year films were also available this deterioration was limited to the firsib year. This slowing of radiological deterioration was not related to 'normalisation' of the्छ erythrocyte sedimentation rate (ESR). Compared with a 'control' group of 10 patients who had refused offers of second line therapy, sulphasalazine treated patients showed less deterioratio $\vec{B}$ over the two year period, and this difference was more marked than in previous studies of gold oथ penicillamine. No significant change was seen in large joint radiographs in sulphasalazine treated patients over two years, but this probably represents the poor sensitivity of the method of assessment. No significant correlation was seen between changes in inflammatory indices and slowing of radiological deterioration in erosion score. Thus sulphasalazine appears to slow the progression of radiological disease of the hands over the second year of treatment in representative sample of patients who continue to receive treatment for two years.

There is evidence that sulphasalazine is an effective second line agent in the treatment of rheumatoid arthritis. ${ }^{1-6}$ Most of the data in these reports relate to the ability of the drug to suppress both the clinical and laboratory features of disease activity and there is no information about outcome measures such as radiological evidence of erosive disease. One of the major practical problems encountered in generating such data is our inability to maintain a truly representative placebo control group over an adequate period $^{7}$ because lack of symptomatic benefit causes patients to withdraw from a placebo group in the first year of study. A number of methods of radiological assessment have been attempted in order to overcome this problem, but none has proved satisfactory. The pre- and post-treatment rates of radiological deterioration (the pretreatment rate was calculated as the immediate pretreatment value divided by disease duration) have been compared, ${ }^{8}$ but this is inaccurate over the longer term since the rate of progression is not linear. ${ }^{9}$ Since second line drugs are 'slow acting', and thus

Accepted for publication 7 November 1986.

Correspondence to Dr T Pullar, Department of Medicine, G Floor, Martin Wing, The General Infirmary, Leeds LS1 3EX. might not be expected to produce an immediate alteration in the rate of radiological progression another method has compared the radiological progression over the first and second six months of treatment. ${ }^{10}$ With this method, only the subgroup of patients who experience a marked laboratory of clinical response show a slowing of progression. ${ }^{11}$ 年 An alternative approach has been to use a seff selected 'control' group consisting of patients with active disease who have consistently refused our offers of second line therapy. ${ }^{13}$ In the study pres sented below we assess the effect of sulphasalazine on the rate of progression during the first arf second years of therapy and also compare the radiological progression of rheumatoid arthritis $\mathrm{R}$ these patients over a two year period with a self selected 'control' group.

\section{Patients and methods}

One hundred and fifty patients with active definito or classical rheumatoid arthritis not controlled first line non-steroidal anti-inflammatory drugs we studied prospectively over a two year period. Patients initially received sulphasalazine $0.5 \mathrm{~g} / \mathrm{da}$, increasing by increments of $0.5 \mathrm{~g} /$ day to $1.5 \mathrm{~g} /$ dây 
(50 patients) or $3 \mathrm{~g} /$ day (100 patients), and subsequently the doses were changed as clinically indicated so that by two years the dose ranged from $1.0 \mathrm{~g}$ to $4.0 \mathrm{~g}$ daily. Clinical and laboratory assessments (ESR, haemoglobin concentration, platelet count, Ritchie articular index, pain score, duration of morning stiffness, and hand grip strength) were carried out at weeks $0,6,12,24$, and at one and two years. A six month follow up of these patients has previously been described. ${ }^{415}$ Radiographs of hands, hip, and knees were taken at 0,1 , and 2 years. Hand radiographs were assessed using a previously described and validated ${ }^{13}$ modification of Sharp's method ${ }^{16}$; hip and knee radiographs were scored using Larsen's standard films ${ }^{17}$ and the four scores for large joints totalled. All films were read blind: hands by TP and large joints by HAC. 'Control' hand radiographs from 0 and 2 year assessments of 10 patients with active disease who repeatedly declined our offers of second line therapy were read blind by TP. The 'control' score on this occasion showed good correlation with the previous reading of these same films four years previously $(r s=0.9625)$. At the start of the study hand radiograph scores did not differ significantly between the 'control' (median 62) and sulphasalazine (median 57) patients ( $\mathrm{p}=0 \cdot 853$; Mann-Whitney).

\section{Results}

Sixty three $(42 \%)$ patients continued to receive sulphasalazine for two years. Forty four discontinued therapy because of adverse effects, 26 stopped because of lack or loss of efficacy, and 17 for miscellaneous other reasons. Hand radiographs at 0 and 2 years were available for 41 patients, 31 of these had hand $x$ rays available for 0,1 , and 2 years. Twenty one patients also had hip and knee radiographs available at 0,1 , and 2 years. No statistical differences in the starting values for any demographic or inflammatory indices could be shown between those who continued therapy and those who stopped, or between any of the subgroups defined by the availability of radiographs (MannWhitney; $p>0.05$ in all cases) (Table 1 ).

Significant improvement in inflammatory parameters between 0 and 2 years was seen in all subgroups. This improvement had occurred by three months and showed no significant change over the subsequent 21 months. Table 1 shows medians, confidence intervals, and $p$ values for the group of 41 patients whose 0 and 2 year films were available and for the 63 patients who completed two years' therapy; a similar pattern was seen in the subgroups of 31 patients who also had one year films and of 21 patients for whom large joint radiographs were available.

Significant deterioration was seen in hand radiograph scores between 0 and 2 years in the 41 patients and in the subgroup of 31 who also had week 48 films. The median changes $(95 \%$ confidence intervals) were $+4(+1-+9)$ and $+5(+1-+9)$ respectively $(\mathrm{p}=0.0004$ and 0.0007 respectively; Wilcoxon $0 \vee 2$ years). The median change in the 'control' group was $+11(+7-+19)(p=0.0367$; Wilcoxon year $0 v 2$ ) (Figs 1 and 2). The change in 'control' values was significantly greater than that in the group of 31 ( $p=0 \cdot 0448$; Mann-Whitney), but the

Table 1 Median (95\% confidence intervals) for inflammatory parameters in the group of patients with 0 and 2 year radiographs $(n=41)$ and the total $(n=63)$ group of patients who completed two years' treatment

\begin{tabular}{|c|c|c|c|c|}
\hline & \multicolumn{2}{|c|}{ Group with radiographs at: } & \multicolumn{2}{|c|}{ Group who completed two years' treatment } \\
\hline & $\begin{array}{l}\text { Oyears } \\
(n=41)\end{array}$ & $\begin{array}{l}2 \text { years } \\
(n=41)\end{array}$ & $\begin{array}{l}\text { Oyears } \\
(n=63)\end{array}$ & $\begin{array}{l}2 \text { years } \\
(n=63)\end{array}$ \\
\hline $\begin{array}{l}\text { Erythrocyte sedimentation } \\
\text { rate }(\mathrm{mm} / \mathrm{h})\end{array}$ & $\begin{array}{l}67 \\
(41-71)\end{array}$ & $\begin{array}{r}33^{* * * *} \\
(20-45)\end{array}$ & $\begin{array}{l}65 \\
(53-70)\end{array}$ & $\begin{array}{l}41^{* * * *} \\
(29-43)\end{array}$ \\
\hline Hacmoglobin $(g / l)$ & $\begin{array}{l}111 \\
(107-116)\end{array}$ & $\begin{array}{l}121^{* * *} \\
(118-127)\end{array}$ & $\begin{array}{l}113 \\
(108-115)\end{array}$ & $\begin{array}{l}119^{*} \\
(116-122)\end{array}$ \\
\hline Platelet count $\times 10^{-4} / 1$ & $\begin{array}{l}427 \\
(345-496)\end{array}$ & $\begin{array}{c}339^{* * * *} \\
(291-398)\end{array}$ & $\begin{array}{l}438 \\
(358-462)\end{array}$ & $\begin{array}{l}341^{* * * *} \\
(333-375)\end{array}$ \\
\hline Ritchic articular index & $\begin{array}{l}12 \cdot 5 \\
(10-19)\end{array}$ & $\begin{array}{l}4^{* * * *} \\
(1-8)\end{array}$ & $\begin{array}{l}17 \\
(12-22)\end{array}$ & $\begin{array}{c}6^{* * * *} \\
(3-11)\end{array}$ \\
\hline Pain score & $\begin{array}{l}2 \cdot 6 \\
(2 \cdot 2-3 \cdot 3)\end{array}$ & $\begin{array}{l}1 \cdot 4^{* * * *} \\
(0 \cdot 9-1 \cdot 7)\end{array}$ & $\begin{array}{l}3 \cdot 2 \\
(2 \cdot 7-3 \cdot 5)\end{array}$ & $\begin{array}{l}2 \cdot 3^{* * * *} \\
(1 \cdot 7-2 \cdot 6)\end{array}$ \\
\hline Duration of morning stiffness ( $\min$ ) & $\begin{array}{l}120 \\
(60-240)\end{array}$ & $\begin{array}{l}12 \cdot 5 * * * * \\
(3-30)\end{array}$ & $\begin{array}{l}60 \\
(60-180)\end{array}$ & $\begin{array}{l}30 * * * * \\
(5-30)\end{array}$ \\
\hline Hand grip strength (mmHg) & $\begin{array}{l}90 \\
(78-104)\end{array}$ & $\begin{array}{l}93^{*} \\
(80-108)\end{array}$ & $\begin{array}{l}88 \\
(75-117)\end{array}$ & $\begin{array}{l}88^{*} \\
(80-105)\end{array}$ \\
\hline
\end{tabular}

Wilcoxon: week $0 v$ week $96^{*}=\mathrm{p}<0 \cdot 05 ;^{* *}=\mathrm{p}<0 \cdot 01 ;{ }^{* * *}=\mathrm{p}<0 \cdot 005 ;{ }^{* * * *}=\mathrm{p}<0 \cdot 001$. 


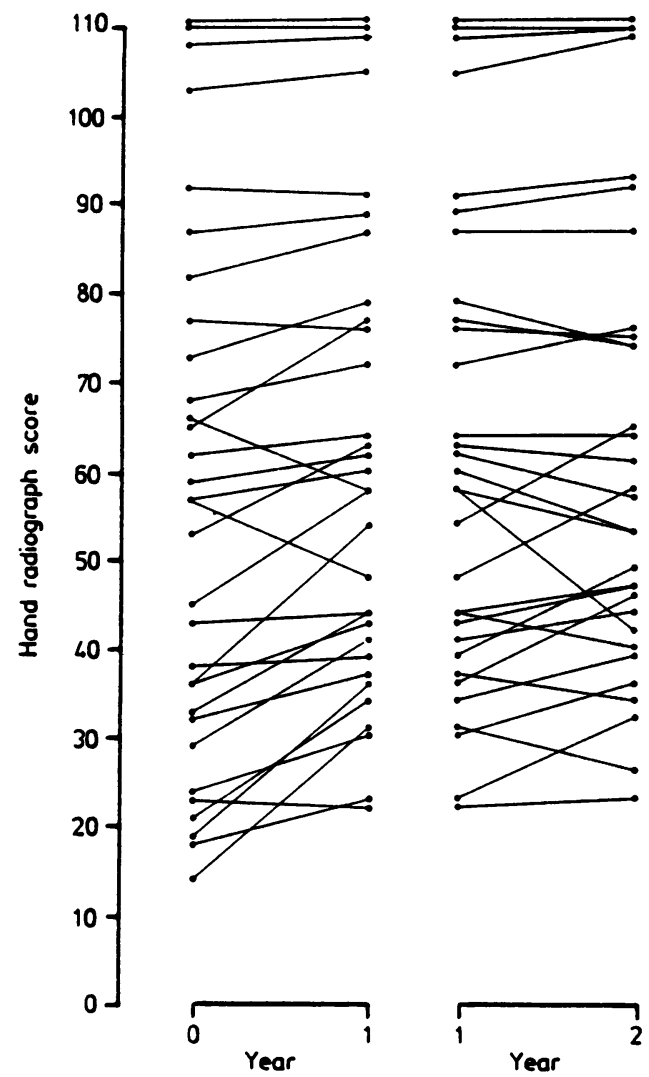

Fig. 1 Change in hand radiograph scores over two years' therapy with sulphasalazine.

difference did not reach statistical significance when compared with the change in the group of 41 patients ( $p=0.0747$; Mann-Whitney).

In the group of 31 patients in whom 0,1 , and 2 year hand films were available a significant deterioration was seen during the first year but no significant change was seen during the second year (Table 2). The degree of change over the first and second 48 week periods also differed significantly $(p=0.0182$; Mann-Whitney). This pattern was maintained even in those 21 patients whose ESR failed to remain below $30 \mathrm{~mm} / \mathrm{h}$ at one and two years, although in this case comparison of the change in the radiograph score over the first and second years failed to reach statistical significance $(p=0 \cdot 106$; Mann-Whitney). In the 10 patients who maintained their ESR at $<30 \mathrm{~mm} / \mathrm{h}$ at one and two years a significant deterioration was seen during the first but not the second year, but again comparison of the change in the radiograph score over the first and second years failed to reach significance $(p=0 \cdot 156$ 을. Mann-Whitney). Large joint radiographs showed a median score of $6(95 \%$ confidence limits 2-9) a a time 0 and of 7 (95\% confidence limits 2-10) at two

Table 2 Change in hand radiographs (median and 95\% confidence intervals)

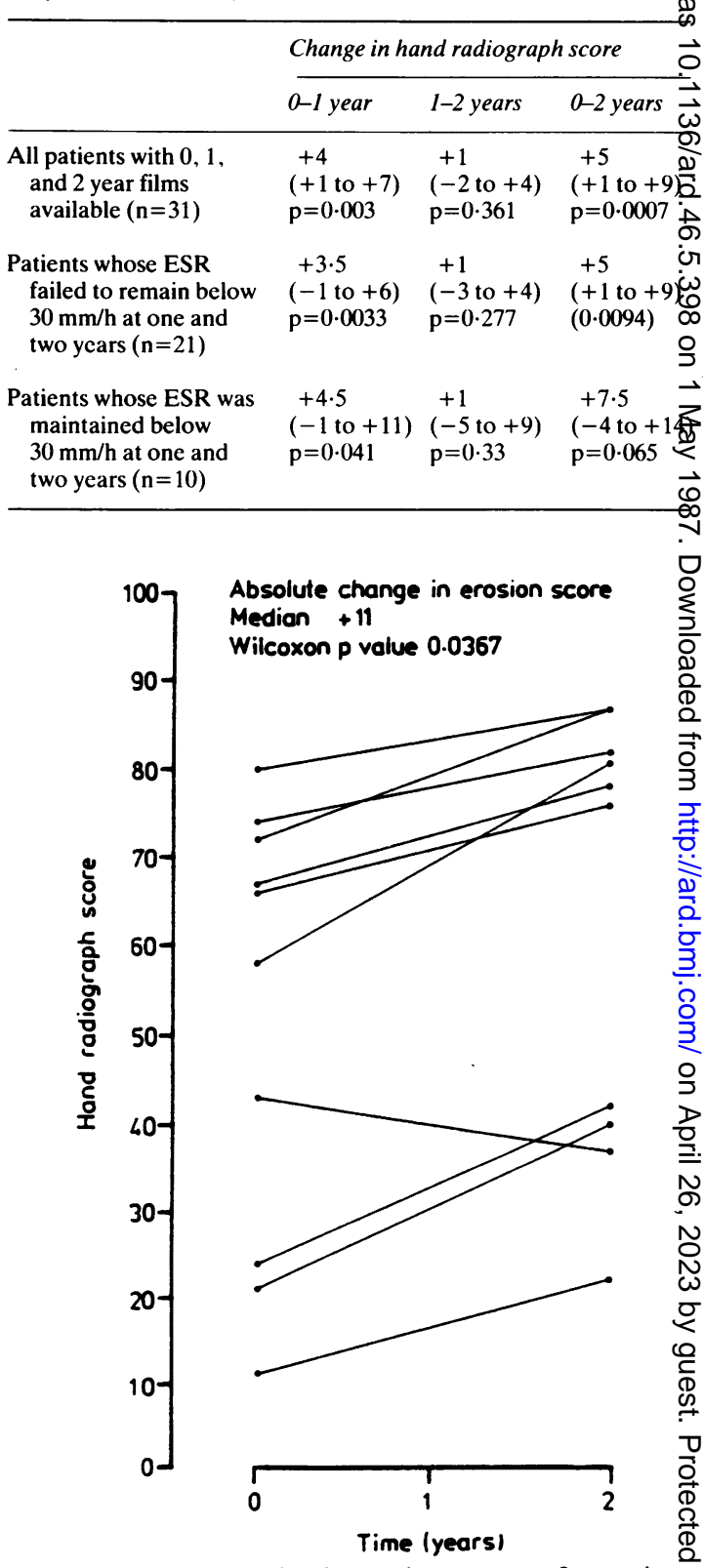

Fig. 2 Change in hand radiograph scores over 2 years in 10 'control' patients. 
years $(p=0 \cdot 059)$. A correlation was seen between the absolute scores for hands and large joints $(\mathrm{r}=0.45, \mathrm{p}<0.0001$; Spearman-Rank $)$ but not between the change in hand and large joint scores. Change in three inflammatory parameters (ESR, articular index, and grip strength) was tested for correlation with radiograph scores. No significant correlations were seen between changes in these inflammatory parameters and changes in either small or large joint radiograph scores at one or two years (Spearman-Rank test; all $\mathrm{p}>0 \cdot 05$ ).

\section{Discussion}

Unfortunately radiographs were not available in all patients who completed two years of therapy. Disease activity at the outset of treatment and changes during treatment, however, were no different in the patients who films were available than in the whole group who achieved two years of therapy.

The most important finding in this study is the slowing of radiological progression during the second year of sulphasalazine therapy. Previously such a slowing with second line drugs has been shown convincingly only in a subgroup of patients whose ESR or $C$ reactive protein returned to normal, ${ }^{11}$ although in that study change in the second six month period was compared with that in the first. In our study the lack of significant deterioration during the second year was seen even in patients whose ESR failed to remain below $30 \mathrm{~mm} / \mathrm{h}$, though it can be assumed that all patients who remained on therapy did show a clinically significant symptomatic improvement compared with week 0 . As in previous studies, change in hand radiograph score did not correlate significantly with change in inflammatory indices, ${ }^{12}$ and this suggests that the criteria which we use to identify a second line drug (improvement in clinical and laboratory parameters of inflammation) are not necessarily important in determining the longer term outcome as measured by radiological changes. Rheumatoid arthritis, however, is a chronic disease and the inflammatory phase can last over 20 years. Thus, although the results described here are promising, it will be necessary to investigate whether this slowing of deterioration continues over subsequent years.

It is also noteworthy that in view of our previous calculation predicting the number of patients who would have to continue to receive gold or penicillamine (120 and 161 respectively) over a two year period (with a similar sized control group) to show a significant difference in the slowing of erosive disease $^{13}$ that we attained $p$ values around the $5 \%$ level with groups of 31 and 41 patients treated with sulphasalazine. Interpretation of this information is difficult. It is possible that sulphasalazine has a more marked effect on radiological progression than does gold or penicillamine, but we have no firm evidence of this, and a formal trial to investigate this point further would require large numbers of patients treated concurrently. An alternative explanation is that the increase in the number of second line drugs had made us less tolerant of partial response to 'second line' therapy-the large numbers of patients discontinuing therapy because of lack/loss of effect would tend to support this possibility. In an ideal world an intention to treat analysis would be an important method of resolving this question. In the real world, however, most patients who discontinue one second line drug proceed to another such agent (over $80 \%$ of patients in our study), and such an analysis would therefore only cloud the issue further.

It is of interest that there was no significant change in large joint radiographs over two years despite a weak correlation between the changes in large joint scores and hand scores. This may reflect a true lack of progression (perhaps related to therapy) but is more likely merely to represent the lack of sensitivity of the semi-objective Larsen method for assessing deterioration in large joints.

No attempt has been made to investigate the relationship of dose of sulphasalazine to radiological progression as at the end of the two year period patients had achieved a wide range of doses which suited them in terms of side effects and symptomatic relief and the numbers on any one dose would have been insufficient for a meaningful comparison to take place.

We conclude that sulphasalazine produced a slowing of radiological deterioration in the small joints of the hands during the second year of therapy in the minority of patients who continue therapy for two years. This effect is independent of improvement in inflammatory parameters. In addition, when compared with a self selected 'control' group there is a tendency, with equivocal statistical significance, for radiological progression to be retarded over the first two years of therapy. Such results are at least promising when compared with our previous assessment of gold and penicillamine. ${ }^{13}$

\section{References}

1 McConkey B, Amos R S, Durham S, Forster P J G, Hubball S, Walsh L. Sulphasalazine in rheumatoid arthritis. $\mathrm{Br} \mathrm{Med} \mathrm{J} \mathrm{1980;}$ 280: $442-4$.

2 Bird H A. Dixon J S. Pickup M E, et al. A biochemical assessment of sulphasalazine in rheumatoid arthritis. $J$ Rheumatol 1982; 9: 36-45.

3 Neumann V C, Grindulis K A, Hubball S, McConkey B, 
Wright V. Comparison between penicillamine and sulphasalazine in rheumatoid arthritis. Br Med J 1983; 287: 1099-102.

4 Pullar T. Hunter J A. Capell H A. Sulphasalazine in rheumatoid arthritis: a double blind comparison of sulphasalazine with placcbo and sodium aurothiomalate. $\mathrm{Br}$ Med J 1983; 287: $1102-4$.

5 Grindulis K A. McConkey B. Outcome of attempts to treat rheumatoid arthritis with gold. penicillamine, sulphasalazinc or dapsonc. Ann Rheum Dis 1984; 43: 398-401.

6 Bax D E, Amos R S. Sulphasalazine: a safe, effective agent for prolonged control of rheumatoid arthritis. A comparison with sodium aurothiomalate. Ann Rheum Dis 1985; 44: 194-8.

7 Pullar T, Capell H A. A rheumatological dilemma: is it possible to alter the course of rheumatoid arthritis? Can we answer the question? Ann Rheum Dis 1985; 44: 134-40.

8 Gofton J P, O'Brien W N. Effects of auranofin on the radiological progression in rheumatoid arthritis. $J$ Rheumatol 1982; 9: 169-72.

9 Sharp J T. Radiographic evaluation of the course of articular disease. Clin Rheum Dis 1983; 9: 541-57.

10 Scott D L, Grindulis K A. Struthers G R, et al. Progression of radiological changes in rheumatoid arthritis. Ann Rheum Dis 1984; 43: 8-17.
11 Dawes P T. Fowler P D. Clarke S. Fisher J. Lawton AD Shadforth M F. Rheumatoid arthritis: treatment which controts? the $C$-reactive protein and erythrocyte sedimentation rate reduces radiological progression. $B r J$ Rheumatol 1986: 250\% 44-9.

12 Scott D L. Dawes P T. Fowler P D. et al. Anti-rheumatic drug and joint damage in rheumatoid arthritis. $Q J$ Med 1985: 54 49-59.

13 Pullar T. Hunter J A. Capell H A. Does second line therap $\mathbb{8}$ affect the radiological progression of rheumatoid arthritis? Ant
Rheum Dis 1984; 43: 18-23.

14 Pullar T, Hunter J A. Capell H A. Sulphasalazine in the treatment of rheumatoid arthritis: relationship of dose and scrum levels to efficacy. $B r J$ Rheumatol 1985: 24: 269-76

15 Pullar T. Hunter J A. Capell H A. Effect of acetylatow phenotype on efficacy and toxicity of sulphasalazine in rheum:to toid arthritis. Ann Rheum Dis 1985: 44: 831-7.

16 Sharp J T. Lidsky M D. Collins L C. Morcland J. Methods of scoring the progression of radiological changes in rheumatoig arthritis. Arthritis Rheum 1971: 14: 706-20.

17 Larsen A. Dales K. Eck M. Radiographic evaluation rheumatoid arthritis and related conditions by standard refe 100 ence films. Acta Radiol /Diagn/ (Stockh) 1977: 18: 481-91옥 